\title{
The effects of repetition on the short-term memory function'
}

\author{
Walter Kintseh \\ UNIVERSITY OF MISSOURI
}

\begin{abstract}
Abstraet
Lists of stimulus items were constructed in such a way that successive presentations of items were always separated by 1 intervening item for one group of items and by 10 intervening items for another group. The S's task was to decide whether he had seen each item before. The amount of forgetting which occurred between presentations was determined both for the short- and longdelay items as a function of the repetition of these items.

\section{Problem}

The verbal learning process has been analyzed into three different events: trace formation on one trial, its utilization on the next trial and short-term forgetting between trials (Melton, 1963). Short-term forgetting has been studied by several investigators (e.g., Peterson \& Peterson, 1959) and an orderly relationship between presentation-test interval and percentage of recall has been obtained. Shepard \& Teghtsoonian (1961) observed a similar relationship between delay since the last presentation of a stimulus item and performance on a recognition test.

The changes which occur in the short-term memory function when an item is repeated were described by Hellyer (1962). Consonant trigrams were given from one to eight presentations before retention intervals varying from 3 to $27 \mathrm{sec}$. Items which were presented only once showed the characteristic steep decline of recall during the first $18 \mathrm{sec}$. Repetition of an item decreased this effect considerably. In the present report the effect of repetition will be investigated using a modified version of the Shepard and Teghtsoonian recognition procedure. The same items were tested after each presentation. A separate learning curve for each presentation-test interval was thus obtained.

\section{Method}

The Ss were given a list of 210 items and were asked to state for each item whether or not it had appeared in the list before ("old" and "new"). A total of four lists were prepared for this experiment. Four-place numbers were used for the first three lists and high association value nonsense syllables for the fourth list. The first three lists were given, to $30 \mathrm{Ss}$ each. The nonsense syllable list was given to $26 \mathrm{Ss}$. All Ss were drafted from an introductory course. Each list contained 20 experimental items which were presented six times. For half of the experimental items successive presentations were separated by one intervening item and for the other half by 10. Dummy items were used wherever necessary. The first 10 items of each list were included as a warm-up task and were disregarded in the results.
Items were typed on $3 \times 5$ in index cards and presented manually from behind a wooden screen for approximately $2 \mathrm{sec}$. Since learning was very fast when the nonsense syllable material was employed, the presentation rate was increased to $1.5 \mathrm{sec}$. per item.

\section{Results}

Recognition of old items: The effects of repetition upon forgetting between trials are summarized in Fig. 1 and 2. More errors were made on items with long delay between presentation and recognition test than on items with a short delay. Difference scores were obtained between the total number of errors each $\mathrm{S}$ made on long-delay and short-dealy items. The hypothesis that the mean difference is zero could be rejected with a high level of confidence for both kinds of learning material $(t=11.81 ; 89 \mathrm{df}$, for the four-place numbers and $t=2.85 ; 25 \mathrm{df}$, for the nonsense syllables).

The differences between the three lists of four-place numbers were not statistically significant, so that the data could be pooled in Fig. 1. The average number of failures to recognize old items was 2.6, 3.4 and 3.1 for the short-delay and $8.4,7.3$ and 6.9 for the long-delay items of the three lists.

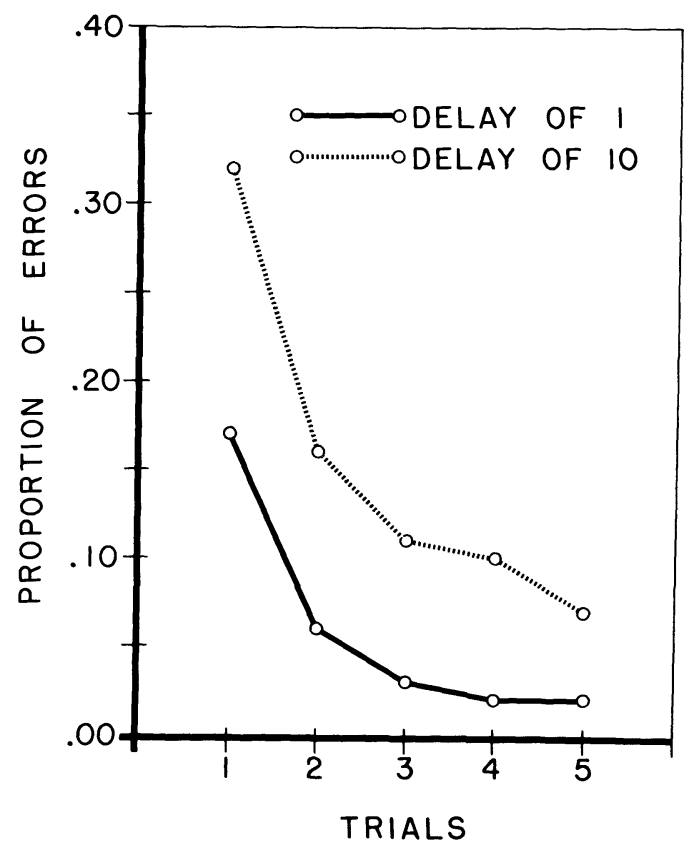

Fig. 1. Proportion of four-place numbers not recognized as a function of repeated presentations. One or 10 other items intervened between successive presentations. 
A comparison of Fig. 1 and 2 shows that short-term forgetting affected performance much more when the four-place numbers had to be learned than when the more meaningful high association value syllables served as learning material. With only one item intervening between successive presentations the nonsense syllables and four-place numbers were learned equally fast but with 10 intervening items the four-place numbers proved to be much more difficult.

False alarm rate: S's readiness to call new items "old" increased slightly throughout the 200 experimental trials. The average false alarm rate was .21. However, the proportion of "old" responses to new items during the first 100 trials was .17 , which increased to .25 during the second half of the trials. Sixty-seven Ss showed an increase in false-alarm rate from the first to the second half of the trials and for 35 Ss a decrease was observed, the rest remaining constant. This difference is highly significant by the sign test.

\section{Discussion}

Less retention after only one presentation of an item was observed in the present study than by Shepard \& Teghtsoonian (1961). This is probably due to the use of four-place numbers instead of three-place numbers as in the earlier study.

The effects of repetition upon recognition memory appear to be quite similar to those observed by Hellyer (1962) with a recall procedure. The large differences in the amount of short-term forgetting after a delay of one or 10 intervening items become smaller as a function of repeated presentations. For both shortand long-delay items a considerable amount of improvement occurred with practice. If one thinks of short- and long-term memory as distinct storage systems the question could be raised whether the obviously superior performance in the short-delay group really reflected better learning (in the sense of longterm storage) or was merely due to fewer short-term forgetting losses.

The items intervening between successive presentations of an experimental item were partly dummy items and partly other experimental items. In the latter case some of the intervening items were often already learned by Ss. Although the interfering effects of new and old items are probably not equal, whatever variability was thus introduced into the data was small relative to the strong effects of the one versus 10 intervening item conditions.

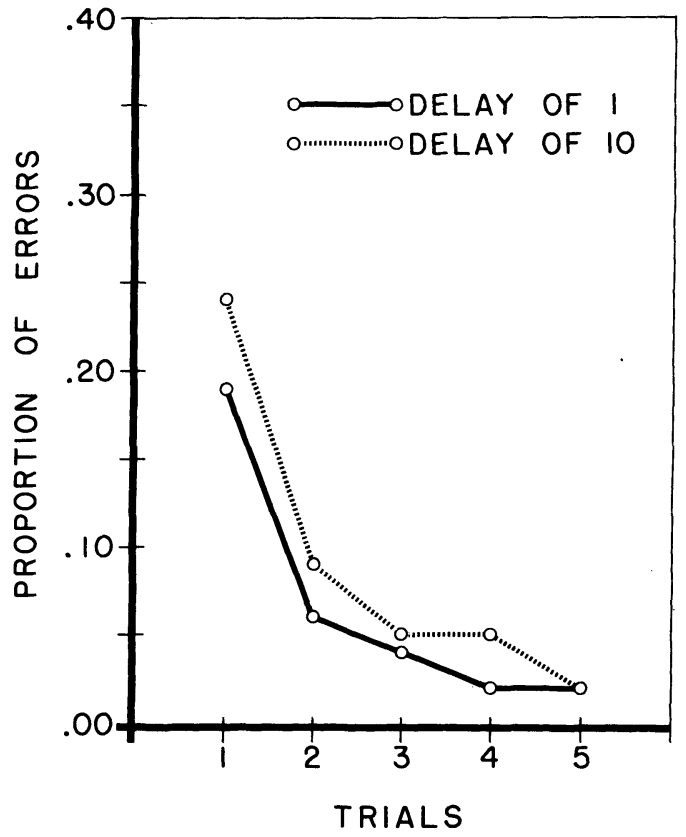

Fig. 2. Proportion of nonsense syllables not recognized as a function of repeated presentation. One or 10 other items intervened between successive presentations.

Learning curves which are very much like the ones obtained here were also reported by Hayes et al (1953) in a study of short-term memory in experienced chimpanzees. The number of items intervening between successive presentations of a discrimination problem affected performance as in the present study.

\section{References}

HAYES, K. J., THOMPSON, R., \& HAYES, C. Concurrent discrimination learning in chimpanzees. J. comp. physiol. Psychol., 1953, 46, 105-107.

HELLYER, S. Supplementary report: Frequency of stimulus presentation and short-term decrement in recall. J. exp. Psychol., $1962,64,650$.

MELTON, A. W. Implications of short-term memory for a general theory of memory. J. verbal Learn. verbal Behav., 1963, 2, 1-21.

PETERSON, L. R。, \& PETERSON, M. J. Short-term retention of individual verbal items. J. exp. Psychol., 1959, 58, 193-198. SHEPARD, R. N., \& TEGHTSOONIAN, M. Retention of information under conditions approaching a steady state. J. exp. Psychol., 1961, 62, 302-309.

Note

1. This research was supported by grant GB-195 from the National Science Foundation. 